\title{
Fasting during Ramadan in patients with adrenal insufficiency
}

M.Chihaoui, W. Grira, M. Yazidi, F. Chaker, H. Slimane

Department of Endocrinology La Rabta hospital- Tunis - Tunisia

\section{Introduction}

Long fasting in patients with adrenal insufficiency could cause hypotension, dehydration or hypoglycaemia. No studies evaluated these risks and there is no recommendations about fasting for these patients.

\section{Aim of the study}

The aim of our study was to evaluate the possible risks of fasting during the month of Ramadan in patients with adrenal insufficiency.

\section{Methods}

Cross-sectional study.

125 subjects, followed up and treated for adrenal insufficiency, were questioned about fasting during the last month of Ramadan (2014) : changes in the modalities of the treatment, eventual complications, number of fasted days.

Mean duration of daily fast during Ramadan 2014 in Tunis was about 14 hours.

Fasters were defined as those who tried to fast for at least one day.

\section{Results}

\section{Distribution by age and sex:}

The average age of our patients : 47,8 years (14-79years).

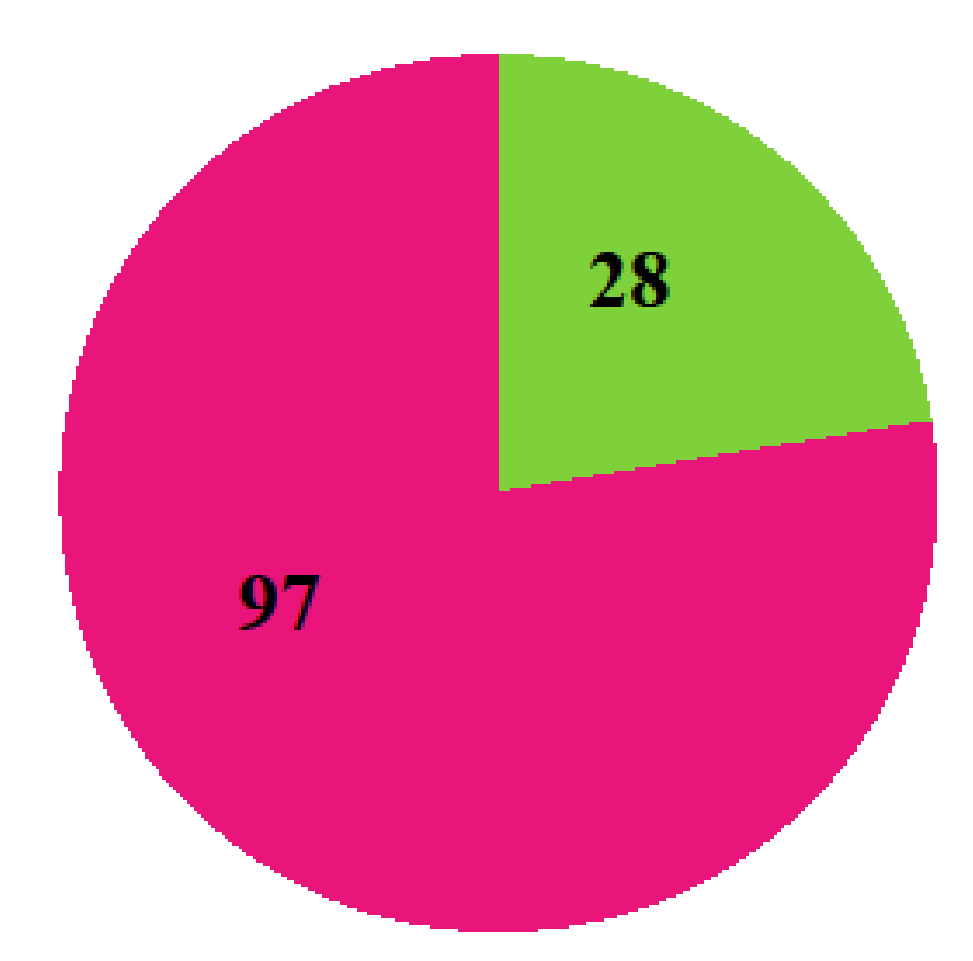

$\square$ Male

- Female

The sex ratio $(\mathrm{M} / \mathrm{F}): \mathbf{0 , 2 8}$.

\section{Distribution according to the etiology:}

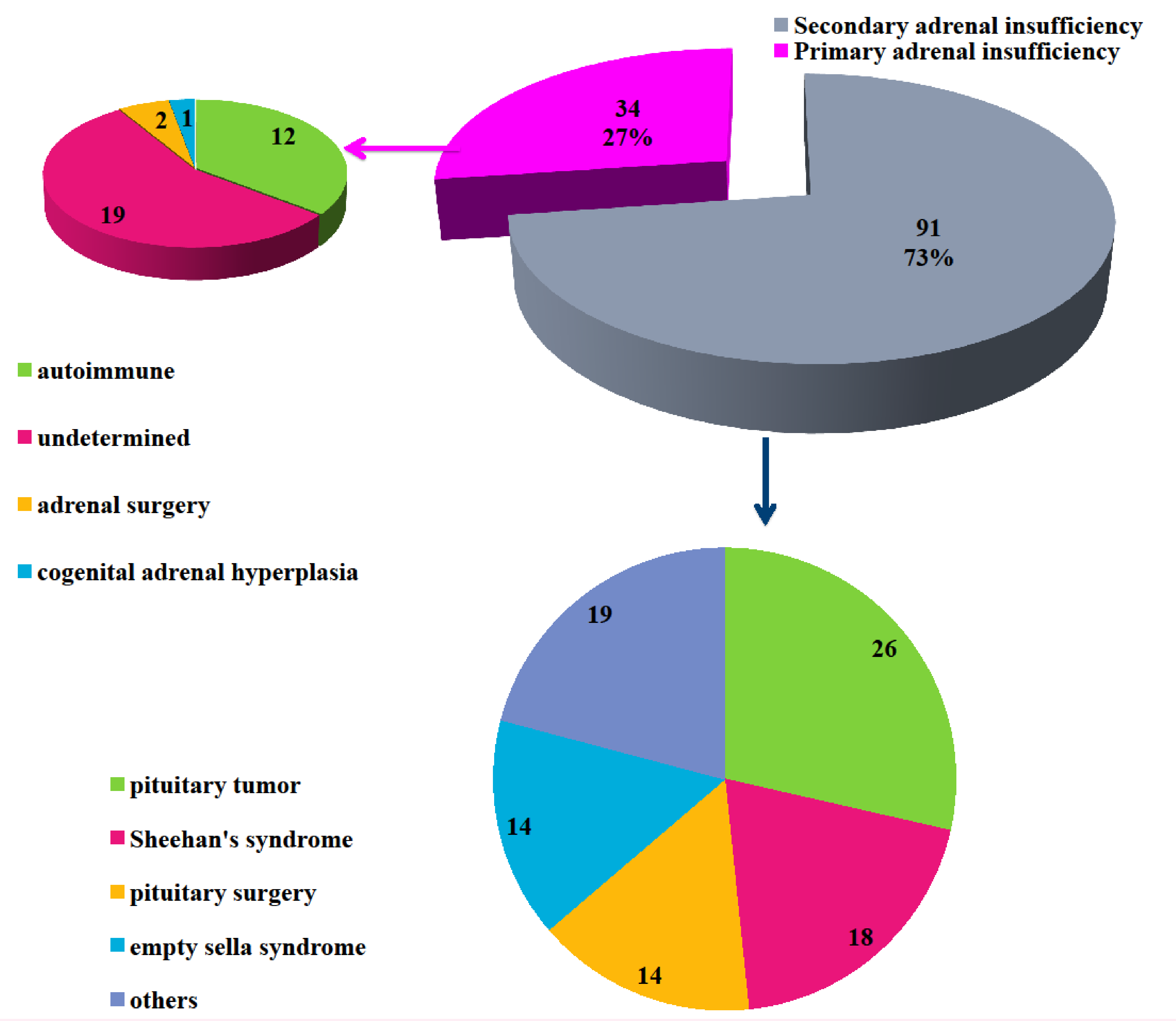

Adherence to medical advice:

59 patients $(47,2 \%)$ tried to fast.

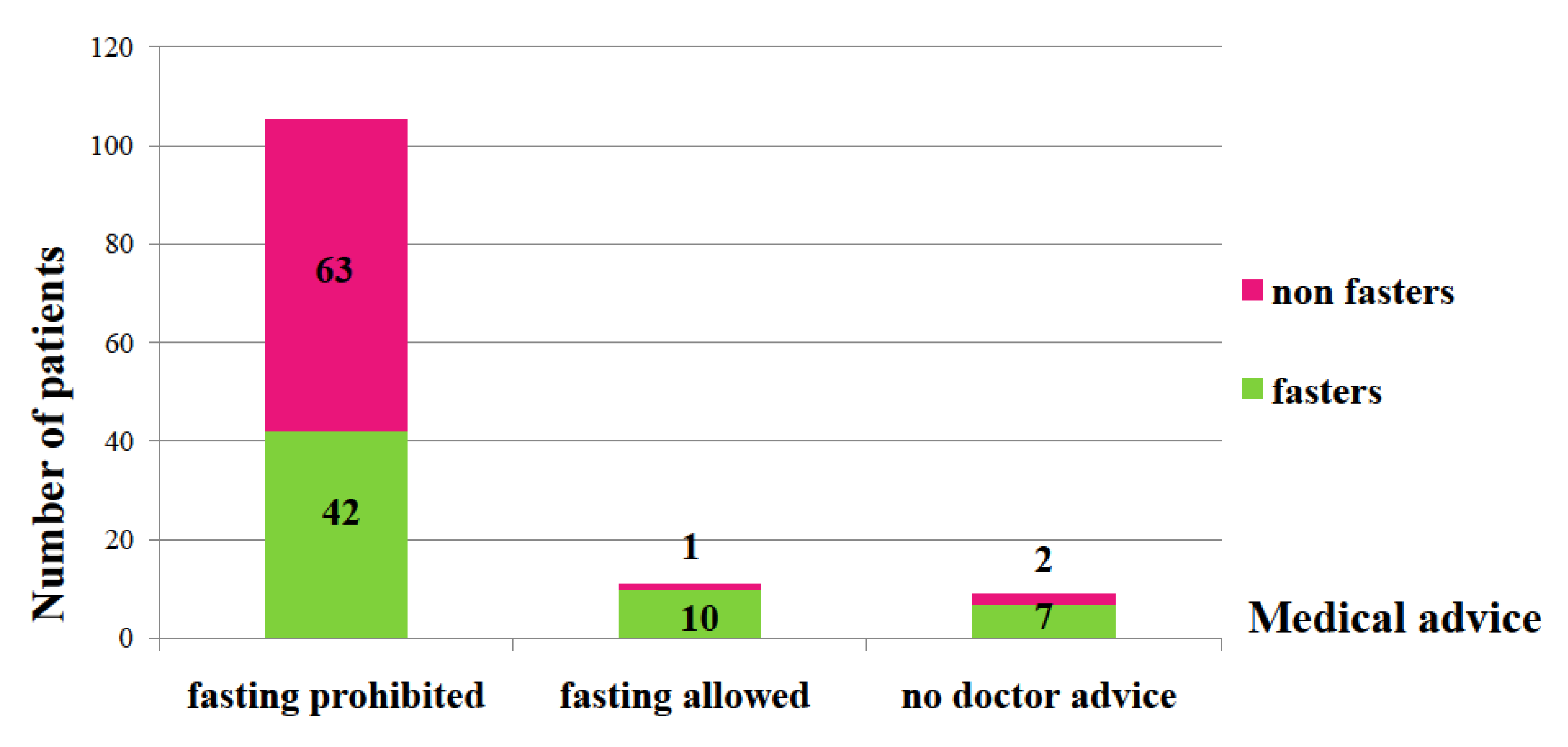

Ability to fast:

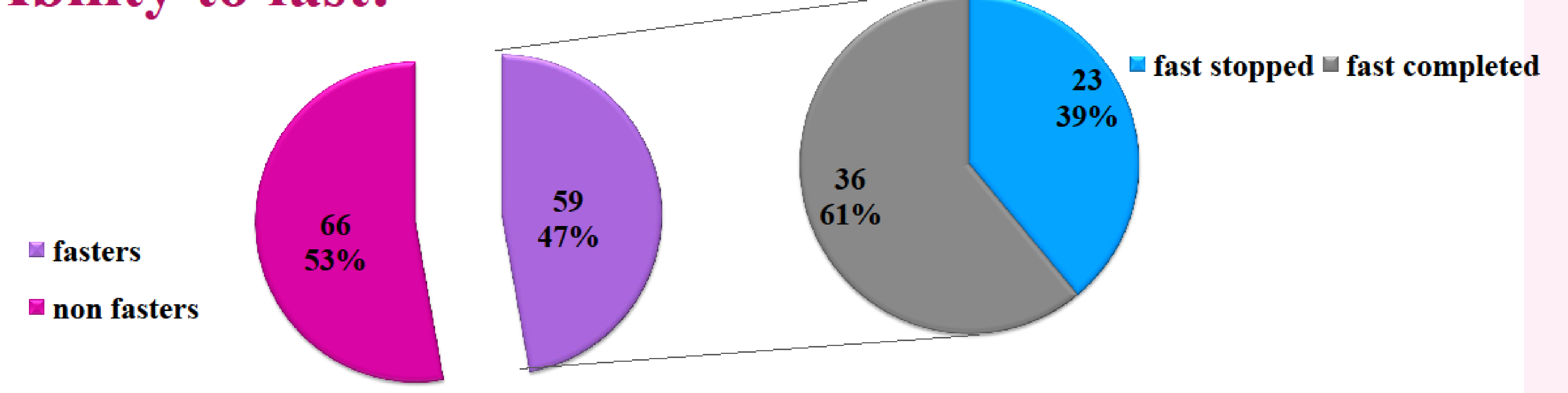

The mean number of fasted days:

20 days (1-29days)

Causes of breaking the fast:

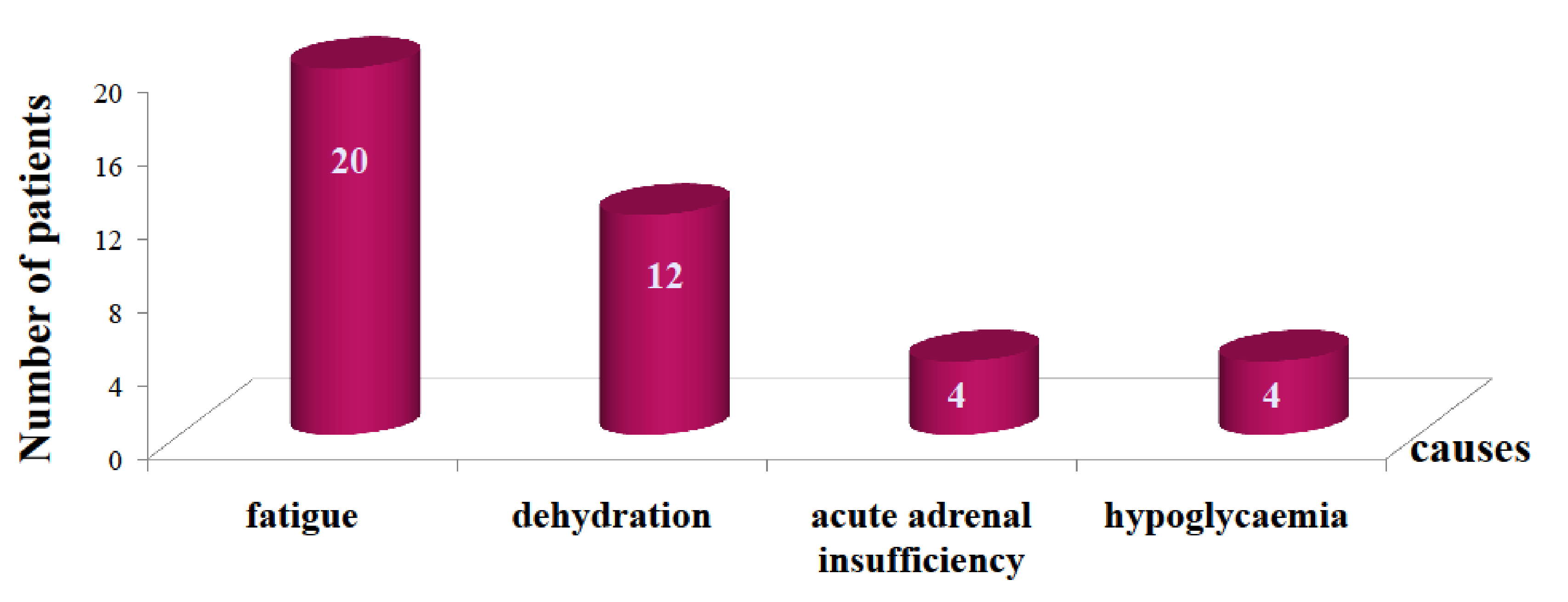

Predictors of breaking the fast:

\begin{tabular}{|l|c|c|c|}
\hline & $\begin{array}{c}\text { patients who could } \\
\text { fast the whole month }\end{array}$ & $\begin{array}{c}\text { patients who } \\
\text { stopped fasting }\end{array}$ & p \\
\hline Age (years) & 47,1 & 49,3 & NS \\
\hline Female & $75 \%$ & $78,2 \%$ & NS \\
\hline $\begin{array}{l}\text { Primary adrenal } \\
\text { insufficiency }\end{array}$ & $17 \%$ & $27 \%$ & NS \\
\hline $\begin{array}{l}\text { Duration of disease } \\
\text { (years) }\end{array}$ & 8,7 & 10,6 & NS \\
\hline $\begin{array}{l}\text { Dose of hydrocortisone } \\
\text { (mg) }\end{array}$ & 20,2 & 21,3 & NS \\
\hline
\end{tabular}

\section{Conclusion}

Fasting during Ramadan can be complicated in patients with adrenal insufficiency, especially in aged patients, a longstanding disease and a primary origin.

More studies are needed to determine patients at risk of complications. A consensus should be established to standardize the management of patients with adrenal insufficiency during the fasting month of Ramadan. 